\title{
Detection of Enteropathogenic Bacteria under Fingernails of Canteen Workers at Universitas Padjadjaran, Jatinangor
}

\author{
Nalinie Nalammah Nahenthran, ${ }^{1}$ Imam Megantara, ${ }^{2}$ Ardini S. Raksanagara ${ }^{3}$ \\ ${ }^{1}$ Faculty of Medicine Universitas Padjadjaran, ${ }^{2}$ Department of Microbiology and Parasitology \\ Faculty of Medicine Universitas Padjadjaran, ${ }^{3}$ Department of Public Health Faculty of Medicine \\ Universitas Padjadjaran
}

\begin{abstract}
Background: Food poisoning is a major problem in Indonesia as most people do not clean under their fingernails to remove bacteria. This study was designed to detect enteropathogenic bacteria under the fingernails of canteen workers in Universitas Padjadjaran, Jatinangor.

Methods: A cross-sectional study was conducted from October-November 2014 at the Faculty of Medicine's Microbiology Laboratory to detect enteropathogenic bacteria under the fingernails of canteen workers in Universitas Padjadjaran, Jatinangor. Based on the inclusion and exclusion criteria of the study, 30 canteen workers were selected by random sampling from three canteens. Samples were collected from the fingernails of both the right and left hands by using a cotton swab. Sixty specimens were cultured for identification of the enteropathogenic bacteria by using gram staining method and biochemical tests.

Results: The highest percentage of enteropathogenic bacteria found under the fingernails of canteen workers was Klebsiella pneumoniae with a percentage of $45 \%$ followed by Enterobacter aerogenes with a percentage of $25.7 \%$, Salmonella paratyphii with a percentage of $9.7 \%$, E. coli with a percentage of $6.4 \%$, and Serratia sp, Proteus mirabillis, Klebsiella oxytoca and Shigella sp. with a percentage of $3.2 \%$.

Conclusions: The highest number of bacteria found under the fingernails of the canteen workers is Klebsiella pneumoniae, followed by Enterobacter aerogenes, Salmonella paratyphii and E. coli which has potential to cause gastroenteritis if cross-contamination occurs between the fingernails and the food. [AMJ.2016;3(2):309-13]
\end{abstract}

Keywords: Canteen workers, fingernails, Klebsiella pneumoniae, resistance

\section{Introduction}

The enteropathogenic bacteria usually inhabit the intestinal gut of humans and animals. These bacteria are regularly pathogenic and can cause disease in humans. Genera like Escherichia, Shigella, Salmonella, Enterobacter, Klebsiella, Serratia and Proteus are included in the enteropathogenic bacteria family. ${ }^{1}$

Transmission of enteropathogenic bacteria is affected directly or indirectly through objects contaminated with feces and these include food, water, nails, and fingers, indicating the importance of faecal-oral human-to-human transmission. Thus, food-handlers with poor personal hygiene are potential sources of infections of many enteropathogenic bacteria. Food may be contaminated by foodhandlers who harbour and excrete intestinal enteropathogenic bacteria from their feces via their fingers to food processing, and finally to healthy individuals. The area beneath the fingernails harbours the most microorganisms and is the most difficult area to clean compared to other parts of the hand. ${ }^{2}$

The spread of infections obtained by external contact can be greatly reduced by hand washing. Hand washing can cause a reduction between $12 \%$ and $40 \%$ of all gastrointestinal diseases and over $20 \%$ of all infections. ${ }^{3}$

Unfortunately, most people do not wash their hands properly and do not use the correct methods of hand washing in their daily lives. ${ }^{4}$ This study was designed to detect enteropathogenic bacteria under the fingernails of canteen workers in Universitas Padjadjaran, Jatinangor.

\section{Methods}

This study was carried out from OctoberNovember 2014 at the Faculty of Medicine's

Correspondence: Nalinie Nalammah Nahenthran, Faculty of Medicine, Universitas Padjadjaran, Jalan Raya BandungSumedang Km.21, Jatinangor, Sumedang, Indonesia, Phone: +62 87726442964 Email: nalinienn@gmail.com 
Microbiology Laboratory. The entire study was approved by the Health Research Ethics Committee Faculty of Medicine Universitas Padjadjaran. This study was a descriptive cross-sectional study and samples were obtained from under the fingernails of thirty canteen workers who were selected from three canteens, namely of the Faculty of Medicine, Faculty of Dentistry and Faculty of Pharmacy at Universitas Padjadjaran, based on the inclusion criteria that all subjects must be canteen workers working in canteens at Universitas Padjadjaran and should be involved in the preparation of food in the canteens. While the exclusion criteria were canteen workers with presence of trauma or injury under their fingernails and onychomycosis. The inform consent was given to the canteen workers before obtaining their samples.

The hyponychium part of their fingernails was then swabbed with a sterile cotton bud and placed in Tryptic soy broth as an enrichment media. The samples were brought to the laboratory for culturing on Mac Conkey agar and testing. Sixty specimens from under the fingernails of the left hand and the right hand of each canteen worker were cultured and the presence of enteropathogenic bacteria was identified. Enteropathogenic bacteria were identified through gram staining, microscopic exam and biochemical tests. The three biochemical tests performed were the Kliger Iron Agar test (KIA), Motility Indole Urease test (MIU) and citrate test. The data was presented in a table. The data of the presence of enteropathogenic bacteria were classified based on the type and frequency of bacteria detected under the fingernails.

\section{Results}

The highest number of bacterial colony was found in the left hand with Klebsiella pneumoniae as the most bacteria found in the hands (Table 1).

Based on the total percentage of enterobacteriaceae that was isolated on the left hand, the highest isolated bacteria was Klebsiella pneumoniae followed by Enterobacter aerogenes, Salmonella paratyphii, E. coli, Shigella sp and Serratia sp. The highest percentage of enterobacteriaceae isolated on the right hand was Klebsiella pneumoniae, followed by Enterobacter aerogenes, Proteus mirabillis and Klebsiella oxytoca (Figure 1).

\section{Discussion}

In this study, $12.9 \%$ of the 30 respondents were positive for enteropathogenic bacterial species comprising Salmonella paratyphii $(9.7 \%)$ and Shigella sp (3.2\%). In addition, other enterobacteriaceae like the Klebsiella $s p$, Enterobacter $s p$, E. coli sp, Proteus mirabillis and Serratia $s p$ were also isolated from their fingernail contents. The presence of enteric bacteria under the fingernails of the canteen workers indicated faecal contamination as these bacteria are found in the gastrointestinal system. The presence of enteropathogenic bacteria such as Salmonella paratyphii and Shigella $s p$ under the fingernails of the

Table 1 Types and Percentage of Enterobacteriaceae Isolated Under the Fingernails of Canteen Workers at Universitas Padjadjaran, Jatinangor

\begin{tabular}{lcccccc}
\hline \multirow{2}{*}{ Bacterial Colony } & \multicolumn{6}{c}{ Results of bacterial culture } \\
\cline { 2 - 7 } & \multicolumn{2}{c}{ Left $(\mathbf{N}=\mathbf{3 0})$} & Right $\mathbf{( N = 3 0 )}$ & \multicolumn{2}{c}{ Total (N=60) } \\
\cline { 2 - 7 } & $\mathbf{n}$ & $\mathbf{0}$ & $\mathbf{n}$ & $\mathbf{9}$ & $\mathbf{n}$ & $\mathbf{\%}$ \\
\hline Salmonella paratyphii & 3 & 9.7 & 0 & 0 & 3 & 9.7 \\
Shigella sp. & 1 & 3.2 & 0 & 0 & 1 & 3.2 \\
E. coli & 2 & 6.4 & 0 & 0 & 2 & 6.4 \\
Klebsiella pneumonia & 10 & 32.2 & 4 & 12.9 & 14 & 45.1 \\
Klebsiella oxytoca & 0 & 0 & 1 & 3.2 & 1 & 3.2 \\
Enterobacter aerogenes & 6 & 19.3 & 2 & 6.4 & 8 & 25.8 \\
Serratia sp. & 1 & 3.2 & 0 & 0 & 1 & 3.2 \\
Proteus mirabilis & 0 & 0 & 1 & 3.2 & 1 & 3.2 \\
Total & 23 & 74 & 8 & 25.7 & 31 & 100 \\
\hline
\end{tabular}




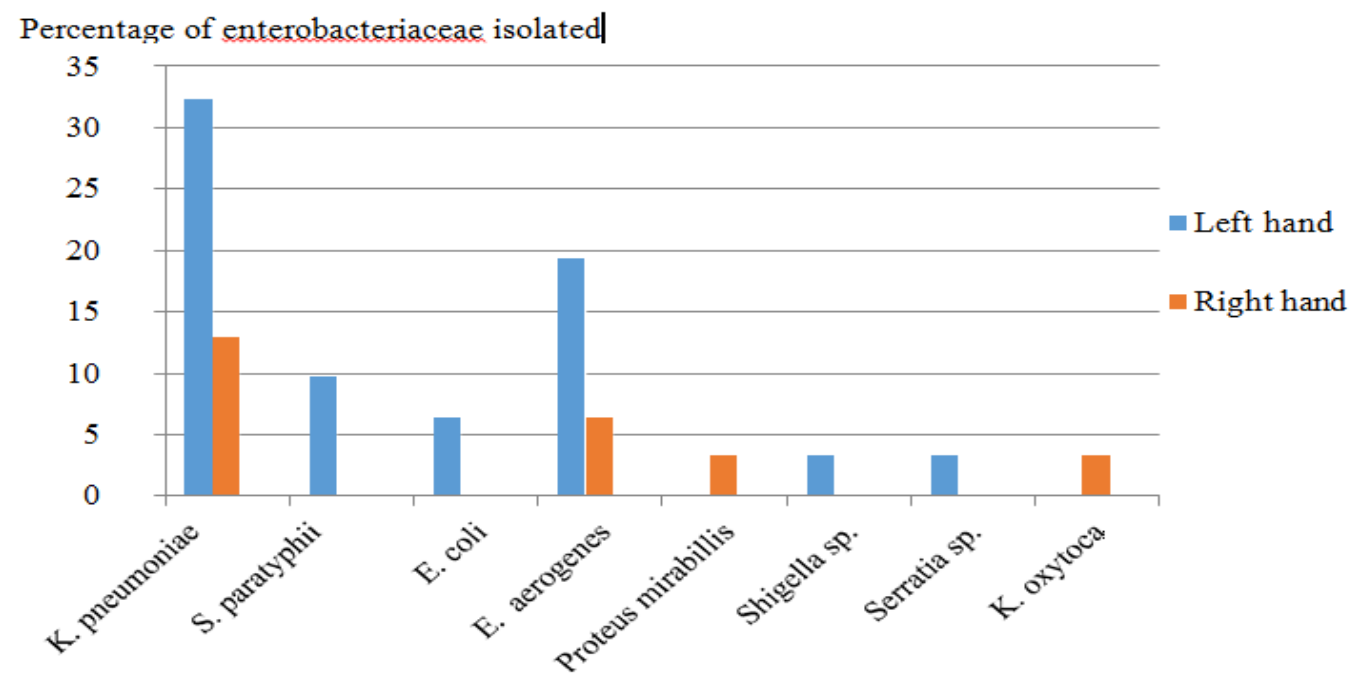

Figure 1 Types and Percentage of Enterobacteriaceae Isolated under the Fingernails

canteen workers at Universitas Padjadjaran, Jatinangor in this study was in agreement with the findings of other studies in the region and other parts of the country.

However, the number of Klebsiella pneumoniae isolated from under the fingernails of the canteen workers had the highest percentage compared to other enterobacteriaceae. As already known, Klebsiella strains can be found in the respiratory tract and feces of about $5 \%$ of healthy adults and the bacteria become pathogenic only when they reach tissues outside of their normal intestine. ${ }^{1} \mathrm{~A}$ pathogen's opportunity for infectivity depends upon its ability to survive on surfaces. Most microorganisms and enteric pathogen that colonize the human intestinal tract have adapted to moist conditions. They either die or grow slowly in a dry environment. ${ }^{5}$ This explains why Shigella sp, Salmonella paratyphii and other enterobacteriaceae were found at a lower percentage under the fingernails of the canteen workers. However, according to a study conducted in Michigan State University, USA, Klebsiella pneumoniae which is also called Klebsiella aerogenes in some countries has a higher survival rate on the fingertips compared to other enteric bacteria. This is simply because Klebsiella pneumoniae is also found in the normal flora of skin. Human skin bacteria are adapted to a dryer existence and this ability may be one reason why Klebsiella pneumoniae survive better on fingertips than other enteric bacteria like E. coli although Klebsiella strains colonize the gastrointestinal tract primarily. ${ }^{5}$ Nevertheless, the higher percentage of Klebsiella pneumoniae found under the fingernails of the left hand compared to the right hand supported the notion of contamination by faecal bacteria due to ineffective hand washing of canteen workers where the usage of a nailbrush might have been abandoned.

However, Klebsiella Pneumoniae plays a minimal role in causing food borne or water borne infections. ${ }^{1}$ Klebsiella pneumoniae is an opportunistic pathogen frequently associated with nosocomially acquired infections of the respiratory tract such as acute bronchopneumonia, typical lobar pneumonia, chronic Klebsiella pneumonia and urinary tract in compromised individuals. In a study conducted in Cambodia ${ }^{12}$, Klebsiella pneumoniae continues to be the second pathogen responsible for community acquired pneumonia in developing countries and Asia. This bacteria is also characterized by its ability to produce adherence factors and acidic polysaccharide capsule that is an important virulence factor which confers resistance to antimicrobial peptides. ${ }^{7}$ Thus, serious concerns should be given by the public health authorities in order to prevent outbreaks of infections and diseases caused by Klebsiella pneumoniae in the community as there were 
high chances for the bacteria to be transferred into the food that was being served to the students.

Furthermore, in a study performed in Malaysia ${ }^{5}$, it is proven that Klebsiella pneumoniae can be transferred to vegetables through poor hygiene practices and improper handling of food. Klebsiella pneumoniae is found to contaminate salad vegetables and fruit juices which has the potential to cause gastroenteritis. These reports show the possibility of the bacteria to survive on food, therefore causing infections especially to those who are immune compromised or has a higher susceptibility towards infection. The ability of the bacteria to form biofilm makes it even a more dangerous threat to the society as it possesses resistance towards antibiotics.

It is known that certain strains of Klebsiella pneumoniae produce a $\beta$ - lactamase enzyme which is an antibiotic degrading enzyme that is responsible to the reduced susceptibility of antibiotics to the biofilm produced by the bacteria. ${ }^{1,10}$ Klebsiella pneumoniae has become typically resistant to extended-spectrum penicillin such as ampicillin, ticarcillin, and piperacillin and also to many cephalosporins due to the production of extended spectrum beta-lactamases (ESBL). ${ }^{10}$ Klebsiella betalactamases are usually susceptible to carbapenems, such as imipenem, and to betalactamase inhibitors, such as clavulanic acid, sulbactam and tazobactam. ${ }^{10}$ However, most recently, Klebsiella bacteria have developed resistance to these class of antibiotics as well. When Klebsiella pneumoniae produce an enzyme known as a carbapenemase, they are referred to as carbapenem-resistant Klebsiella pneumoniae (CRKP). ${ }^{13}$ This is considered a threat to the safety of the community because carbapenem antibiotics are often the last line of defense against gram-negative infections that are resistant to other antibiotics.

On the other hand, Enterobacter Aerogenes, which was the second most enterobacteriaceae that was isolated under the fingernails, ferments lactose and causes a wide range of nosocomial infections which includes pneumonia and urinary tract infections when they reach tissues outside of their normal intestine such as the urinary tract and lungs. ${ }^{1}$ Enterobacter Aerogenes may be found living freely as well as in the intestinal tract. This explained the reason why Enterobacter Aerogenes was also found under the fingernails of the canteen workers at Universitas Padjadjaran, Jatinangor. It is also known as an opportunistic pathogen. This is when normal host defenses are inadequate particularly in old age, in the terminal stages of other diseases, after immunosuppression, or ith indwelling venous or urethral catheters that can result in localized clinically important infections. The bacteria may reach the blood stream and cause sepsis. ${ }^{1}$

In the process of the study, one limitation was found which was the sample size used that was only 30 . This was due to the cost of microbiological examinations and time constraint. Therefore, the author was unable to use advanced analysis to make associations with the risk factors found in this study.

It can be concluded that the highest number of bacteria found under the fingernails of the canteen workers at Universitas Padjadjaran, Jatinangor is Klebsiella pneumoniae, followed by Enterobacter Aerogenes, Salmonella paratyphii and E. coli which has potential to cause gastroenteritis if cross-contamination occurs between the fingernails and the food. However, other enterobacteriaceae which are also part of the normal flora of the gastrointestinal system that incidentally cause diseases such as Serratia sp, Proteus mirabillis, Shigella sp. and Klebsiella oxytoca are also isolated under the fingernails of these canteen workers. This study may give an impression that there is a microbial contamination under the fingernails of the canteen workers at Universitas Padjadjaran, Jatinangor that may cause public health problems

\section{References}

1. Brooks GF, Carroll KC, Butel JS, Morse SA. Jawetz, Melnick, Adelbergs Medical Microbiology. 24 $4^{\text {th }}$ ed. New York: McGrawHill Companies; 2007.

2. Andargie G, Kassu A, Moges F, Tiruneh M, Huruy K. Prevalence of bacteria and intestinal parasites among food-handlers in Gondar Town, Northwest Ethiopia. J Health Popul Nutr. 2008;26(4):451-5.

3. Kim EJ, Pai AJ, Kang NE, Kim WK, Kim YS, Moon HK, et al. The effects of food safety education on adolescents' hand hygiene behavior: an analysis of stages of change. Nutr Res Pract. 2012;6(2):169-74.

4. Setyautami T, Sermsri S, Chompikul J. Proper hand washing practices among elementary school students in Selat sub-district, Indonesia. J Pub Health Dev.2012;10(2):3-20.

5. Todd EC, Greig JD, Bartleson CA, Michaels BS. Outbreaks where food workers have been implicated in the spread of foodborne 
disease, Part 6: transmission and survival of pathogens in the food processing and preparation environment. J Food Prot. 2009;72(1):202-19.

6. Ryan KJ, editor. Sherris medical microbiology: an introduction to infectious diseases. 4th ed. New Yorks: McGraw-Hill Companies; 2004.

7. Campos MA, Vargas MA, Regueiro V, Llompart CM, Albertí S, Bengoechea JA. Capsule polysaccharide mediates bacterial resistance to antimicrobial peptides. Infect Immun. 2004; 72(12):7107-14.

8. Tumbarello $M$, Spanu $T$, Sanguinetti M, Citton R, Montuori, Leone $F$, et al. Bloodstream infections caused by extended-spectrum- $\beta$-lactamaseproducing Klebsiella pneumoniae: risk factors, molecular epidemiology, and clinical outcome. Antimicrob Agents
Chemother. 2006;50(2):498-504.

9. Bagian Mikrobiologi Fakultas Kedokteran Universitas Padjadjaran. Penuntun Praktikum Bagian Mikrobiologi Fakultas Kedokteran Universitas Padjadjaran. Jatinangor: Bagian Mikrobiologi Fakultas Kedokteran Universitas Padjadjaran; 2010.

10. Pusapanadan S, Afsah-Hejri L, Loo YY, Nillian E, Kuan CH, Goh SG, et al. Detection of Klebsiella Pneumoniae in raw vegetables using more probable number-polymerase chain reaction (MPN-PCR). International Food Research Journal. 2012;19(4):175762.

11. Arnold RS, Thom KA, Sharma S, Philips M, Johnson JK, Morgan DJ. Emergence of Klebsiella pneumoniae carbapenemase (KPC)-producing bacteria. South Med J. 2011;104(1):40-5. 